\title{
Developing a multi-disciplinary public health specialist workforce: training implications of current UK policy
}

\author{
D Evans, S Dowling
}

J Epidemiol Community Health 2002;56:744-747

$\mathrm{D}$ eveloping multi-disciplinary public health training is an international as well as national public health issue. In the UK, recent government health policy has emphasised the importance of developing multi-disciplinary public health activity to improve the nation's health. The English white paper Saving Lives: Our Healthier Nation recognises that the current lack of career pathways for non-medical public health specialists is a major barrier to a genuinely multidisciplinary public health approach. Non-medical public health specialists do not have the comprehensive training, professional development, and career structures currently available to public health doctors. Medical trainees undertake a regionally based but nationally recognised five year specialist registrar training programme leading to inclusion on the General Medical Council specialist register. A number of structured training schemes for those from backgrounds other than medicine have been introduced in some NHS regions; however, these schemes vary considerably. There is, as yet, no similar "gold standard" accreditation comparable to entry on the medical specialist register. If the UK government is to achieve its goals of a genuinely multi-disciplinary public health specialist workforce, then it will need to ensure there is a common high standard of training and appropriate career pathways for medical and non-medical public health specialist trainees. As more non-medical specialists are trained in the NHS, the increasing global dimension of public health policy will require further international cooperation in developing multi-disciplinary public health careers.

\section{INTRODUCTION: THE POLICY CONTEXT}

Over the past 20 years it has been increasingly recognised that major public health issues transcend both national boundaries and disciplinary paradigms. ${ }^{1}$ HIV/AIDS is just one of the many global public health issues that demands an international and multi-disciplinary response. ${ }^{2}$ In a number of countries including Australia, New Zealand, and the United States, the specialist contribution of a range of disciplines to the public health workforce has long been accepted, although as in the US tensions may remain over the wider relation between public health and medicine. ${ }^{3}$

Within Europe, there has been historical diversity in the extent to which public health leadership has been viewed as a medical or a multi-disciplinary domain. More recently, increasing European cooperation has led to the identification of the need for a multi-disciplinary public health workforce that is able to work in partnership across national boundaries. ${ }^{45}$ Recent efforts to integrate European public health training have included the establishment of the Association of Schools of Public Health in the European Region and the development of the European Master Programme in Public Health. ${ }^{6}$ One of the goals of this programme is to "create a competence in European public health for a European specialist, that is a person able to move easily across countries and who is familiar with public health problems at a European level." However, current training and career structures are very diverse. Only four European states (the United Kingdom, Ireland, France, and Finland) formally recognise the speciality of the "public health medicine", ${ }^{7}$ and there is substantial variation in the degree to which senior public health positions are commonly available to professionals from a range of disciplines. This paper describes recent developments in multi-disciplinary public health training in the UK context, and identifies the implications for future policy.

Since 1997, UK government health policy has emphasised the importance of multi-disciplinary public health activity to improve the nation's health. In England, this policy was articulated in the 1999 white paper Saving Lives: Our Healthier Nation and re-affirmed in the recent Report of the Chief Medical Officer's Project to Strengthen the Public Health Function. ${ }^{89}$ An important element of this policy is a commitment to broaden the NHS public health workforce from its traditional medical base to include "people from a wide range of professional backgrounds". ${ }^{8}$ The need for this change is justified by the range of roles undertaken by specialists in public health (for example, communicable disease control, tackling inequalities, and the wider determinants of health), the correspondingly breadth of expertise they need to demonstrate, and thus the range of disciplines they need to draw upon. ${ }^{9}$ This policy commitment to a more multi-disciplinary workforce has generated continuing debate within the public health field with many advocates of change, ${ }^{10-13}$ but also continued resistance, particularly from within the Faculty of Public Health Medicine (hereafter Faculty) and the BMA. ${ }^{13}{ }^{14}$ A key area of uncertainty has been the implications of this policy shift for the training of public health specialists.

Saving Lives argues that the potential benefit of a more multi-disciplinary approach is huge, but also recognises a number of barriers. In particular, it highlights the lack of career pathways for non-medical public health specialists:

First is the absence of a true multi-disciplinary basis to public health practice. In the past the rhetoric has been strong but it has not always been followed through into practice. Those without medical backgrounds have had to put together 'do it yourself' careers in public health. Even then they have often had relatively low status and recognition for their skills and expertise. ${ }^{8}$

The white paper, however, only sketches the organisational and cultural barriers to developing a multi-disciplinary public health specialist workforce in the NHS. Fundamental to these barriers are questions of the classification, training, registration, and professional development of non-medical public health specialists. Three broad categories of practitioners have been identified and widely accepted as making up the public health workforce ${ }^{915}$ : (1) most people including teachers, business people, and transport engineers; (2) a smaller number for whom public health practice is a fundamental part of their professional role with individuals, groups, or communities 
(such as health visitors or community development workers); and (3) public health specialists who work at a strategic or senior management level or with specialised expertise. Different levels of training, skills and experience are required to carry out these roles. While recognising that the training needs of the wider workforce and public health practitioners are also crucial, they are beyond the scope of this discussion. This paper focuses on the training needs of those who will carry out specialist public health roles at a senior level.

\section{CLASSIFICATION}

The classification of UK public health doctors has been relatively straightforward in recent years. Job titles such as "specialist registrar in public health medicine", "consultant in public health medicine" or "consultant in communicable disease control" have needed little explanation. What to call those from backgrounds other than medicine has been more problematic. "Public health specialist" does not have a universal meaning or application to a defined range of occupations. Some have resisted the move to label those who are not doctors as "non-medical", arguing that it is inappropriate to define a role by what it is not and that this reinforces medicine as the dominant discipline.$^{16}$ However, in the absence of a universally acceptable alternative, the term "non-medical public health specialist" is used in this discussion.

\section{TRAINING IN PUBLIC HEALTH FOR DOCTORS}

Until recently, specialist public health training in the UK has been virtually synonymous with public health medicine training. Following the establishment of the Faculty in 1972, public health doctors have placed great emphasis on developing and maintaining a high quality specialist public health training scheme. This scheme is organised as part of the overall system of specialist medical training, which was reformed after a major national review in 1993. ${ }^{17}$ These "Calman reforms" followed European Community directives to ensure that postgraduate medical education was compatible across Europe. ${ }^{7}$ Public health trainees usually undertake a five year training period as a specialist registrar. Although there is some regional variation, it is usual for this period to include study on an academic programme to gain a Masters in Public Health, as well as a placement in one or more health authorities. Trainees have a defined set of competencies to be achieved and processes (such as the "record of in training assessment" interview) through which progress is formally assessed. The Faculty sets standards, approves regional training schemes, runs the qualifying examinations, and recommends successful candidates for inclusion on the General Medical Council specialist register. ${ }^{18}$ As with other higher specialist training organised through the medical Royal Colleges, the Faculty is deeply embedded in regional public health training committees, with the local Faculty Adviser playing a leading part, often as chair of the committee. Training in public health medicine is well established and funded compared with public health training for other professional groups.

\section{TRAINING IN PUBLIC HEALTH FOR NON-MEDICAL SPECIALISTS}

Until recently, there have been no formal training schemes for non-medical personnel in public health. Over the past few years, however, non-medical public health specialist training schemes have developed in a piecemeal manner in six of the eight English NHS regions, with the remaining two regions currently planning schemes. To date, no training schemes have been developed in Scotland or Northern Ireland, although a scheme is planned to start in Wales in 2002. At the beginning of 2002 there were 40 non-medical trainees on the six established schemes; in comparison there were 433 specialist registrars in training at the same time. It is only very recently that there has been any national initiative to coordinate the emerging non-medical schemes and it is still unclear to what extent this will take place. Funding for non-medical training schemes has come from a variety of sources, including Non-Medical Education and Training budgets at a local level. For some regions, this has resulted in a less well funded system than that used for training public health doctors; in others it has resulted in insecure and short-term arrangements. There is considerable variation in the structure of the non-medical training schemes including their length, trainees' level of salary, the qualifications candidates are expected to gain, and the extent to which they are seen as equivalent to the medical training scheme (S Dowling $S$, oral presentation at 4th South West Public Health Conference, May 2000). Recently, informal discussions have begun between those responsible for running some schemes in an attempt to minimise differences in structure, pay, and conditions of employment.

Some medical public health trainees and consultants in public health have argued both that such training schemes provide a "short cut" to specialist practice for those from nonmedical backgrounds and that a background in clinical medicine is essential to the practice of public health. ${ }^{19}$ It is important to recognise that even though this can be cogently argued against, ${ }^{132}{ }^{21}$ it remains a point of view that is strongly held by a minority of doctors, including those in training. Those responsible for training schemes for non-medical public health specialists, as well as those in training, need to be aware of this and explicitly address concerns about standards of recruitment and professional practice.

\section{PROFESSIONAL REPRESENTATION, STANDARD SETTING, AND REGISTRATION}

There have been a number of recent inter-related initiatives to develop professional representation, standards, and registration for non-medical public health specialists. Until recently, there was no one professional organisation for non-medical public health specialists. From the early 1990s, a number of non-medical public health specialists have sought to persuade the Faculty to broaden its membership to include non-medical specialists. ${ }^{1622}$ A pressure group, the Multidisciplinary Public Health Forum, was formed and began tripartite discussions with both the Faculty and the Royal Institute of Public Health. This strategy has been increasingly successful with the appointment of a number of non-medical specialists as honorary members during the 1990s and the Faculty's decision in 1998 to open Part I of its professional examinations to non-medical candidates, and to confer "diplomate membership" on those who are successful. Although resistance to this change remained strong, ${ }^{13}$ in June 2001 the Faculty voted to open Part II, which leads to full membership, to non-medical applicants. For some nonmedical public health specialists, there is a further debate over whether the Faculty is the appropriate organisation to represent, set standards for, and recommend such practitioners for registration. Concerns focus on whether the Faculty's approach to specialist training and registration promotes an elitist "medical model" that might inhibit the development of a more genuinely multi-disciplinary and inter-sectoral approach to public health.

The Multi-disciplinary Public Health Forum and the Tripartite Group have also been the catalyst for the development of standards for multi-disciplinary public health. For some time the Faculty has been responsible for identifying and maintaining standards for public health medicine training and practice, but no similar standards have existed for non-medical public health. In 1999 the London School of Hygiene and Tropical Medicine published a feasibility study for such standards on behalf of the English Department of Health..$^{23}$ The department then commissioned Healthwork UK, the national training 
organisation for the health service, to undertake a national project to identify and produce standards for public health practice. ${ }^{24}$ These standards are currently being piloted in the English regions.

Unlike medical public health specialists, there is no recognised register for public health specialists similar to that held by the General Medical Council. Once again, the Tripartite Group has been the focus for discussion. It is generally agreed that the Faculty itself would not be an appropriate body to hold such a register. However the Royal Institute of Public Health has been suggested as an appropriate registration body as it carries out this function for other professional groups. It now seems likely that the Royal Institute will hold a voluntary register of public health specialists, as a first step towards a longer term goal of a mandatory register. As with Faculty membership, there is both support for this proposal but also concern about the potentially divisive impact within the wider public health movement.

\section{CAREER STRUCTURES AND CONTINUING PROFESSIONAL DEVELOPMENT}

Saving Lives noted that non-medical public health specialists lack a career structure. As well as the issues of professional representation, standards, and registration discussed above, there are no structures for continuing professional development and career advancement. Prior to Saving Lives, NHS posts as directors of public health were explicitly limited by Department of Health guidance to medically qualified applicants and many other senior NHS public health posts were similarly restricted in practice. A number of non-medical professionals working within NHS public health departments have come from health promotion backgrounds, and in many cases health promotion units are organisational subunits of public health departments. However, the responsibilities and salaries of health promotion specialists clearly mark them out as of lower status than medical public health specialists.

The white paper announced a number of initiatives to overcome the barriers to the development of a genuinely multi-disciplinary public health function. These include the production of a National Public Health Workforce Development Plan, the completion of a Public Health Skills Audit, the creation of a Public Health Development Fund, and the establishment of the post of specialist in public health that "will be of equivalent status in independent practice to medically qualified consultants in public health medicine and allow them to become directors of public health". ${ }^{8}$ This planned "equivalence" will necessitate similar, though not necessarily identical, high quality training and rigorous assessment processes. In principle, it should expand the public health specialist workforce by attracting high calibre people from a wealth of backgrounds.

The details of national initiatives to develop multidisciplinary public health, and the post of specialist in public health in particular, are likely to be made clear in the imminently expected National Public Health Workforce Development Plan. After the white paper and the Report of the Chief Medical Officer's Project, there can be little doubt of the national policy commitment to multi-disciplinary public health. The questions that remain relate to the amount of central resource that will be committed and the degree to which the centre will prescribe the mechanisms to achieve a multi-disciplinary workforce and the creation of specialist posts at a local level.

\section{CONCLUSIONS}

The UK government has clearly stated its policy goals for public health development. It wishes to develop a genuinely multi-disciplinary public health specialist workforce in the NHS and the creation of the non-medical post of specialist in public health "of equivalent status" to consultants in public

\section{Key points}

- Recent UK government health policy has emphasised the importance of developing multi-disciplinary public health activity to improve the nation's health.

- New public health specialist training schemes for those from backgrounds other than medicine have been introduced in some English regions.

- Continuing barriers to multi-disciplinary public health include the absence of clear policy aims and non-equivalent training, registration and career pathways.

- The UK government needs to ensure a common high standard of training and consider a national register for non-medical trainees.

- As more non-medical specialists are trained in the UK, international cooperation will be required in developing multi-disciplinary public health careers.

health. To date, however, the approach to achieving these policy goals has been at an early developmental stage. There has been no national guidance on the model of training to be developed and the English regions have adopted different approaches ranging from an integrated medical and nonmedical training scheme to no non-medical scheme whatsoever. Fundamental questions remain unanswered although they seem crucial to the effective development of training for public health specialists. Are public health specialists being trained to occupy different roles to their medical colleagues or to bring to the same roles a diversity of professional backgrounds and education? If non-medical specialists are to be genuinely equivalent, then it will be difficult to sustain the current disparities in training arrangements, particularly in terms of length and breadth of training, and registration processes. If the roles differ, what are these distinct roles and how are they different? If medical and non-medical public health specialists are to occupy different occupational positions why are so many training schemes choosing to follow the existing medical model of training? The importance of these questions was reflected in the House of Commons Health Committee's March 2001 report that critiqued the English public health function. ${ }^{25}$ The report supported the policy moves in Saving Lives ${ }^{8}$ towards more multi-disciplinary public health. The Committee suggested that public health medicine had been too focused on the "science" of public health rather than on the practice of "hands-on population based approaches to health in the field"; it called in particular for the development of public health leadership skills within primary care organisations and local strategic partnerships with local authorities and the voluntary sector.

Subsequent English policy changes announced in Shifting the Balance of Power $^{26}$ (and further detailed by ministerial speeches $)^{27}$ have clarified the intention to develop a truly multi-disciplinary public health workforce, led at primary care organisation level by directors of public health and focusing on tackling the wider determinants of health. These posts will be open both to doctors and to public health specialists from backgrounds other than medicine. The implication in this policy is of a unified profession working to improve the health of the population it serves. To deliver this policy requires fully integrated training of public health specialists from a variety of professional backgrounds. The role of public health specialists, and the degree of multi-disciplinarity is less clear at higher tiers of the NHS: strategic health authorities (subregional), government offices of the regions and nationally. There has been no guidance to date, for example, on the prospects for opening regional director of public health posts to 
non-medical candidates. It may be that the government eventually concludes that different functions and thus different skills are required at the different levels of the health system.

There have been a number of other recent significant steps towards the UK policy goal of equivalence for medical and non-medical specialists. National work has been commissioned from Healthwork UK to develop common standards; the Faculty voted in June 2001 to open its Part II examination and membership to non-medical applicants; the Tripartite Group is working towards a voluntary register of multidisciplinary public health specialists. At the same time, however, non-medical specialists are still some way from equivalence with their medical colleagues. There is still debate within the public health field on both the principle and the practicalities of the voluntary register and, even if implemented, it is likely to be some time until it is fully functional. Neither has there been national guidance on the key question of non-medical responsibilities for control of infection within the public health specialist role. Thus the government has not yet provided the mechanisms that will allow it to achieve its policy goals. There are three key central tasks. Firstly, the government needs to ensure that all non-medical training schemes provide a comparable quality and depth of specialist training as that provided by the existing medical schemes. Secondly, it needs to examine the benefits and costs of establishing a multi-disciplinary specialist register. Thirdly, it needs to give clear policy guidance on the role and range of responsibilities of the non-medical specialist in public health, opening up senior posts including responsibilities for infection control. Only then is it likely to achieve its policy goals of a genuinely multi-disciplinary public health specialist workforce in the UK. Finally, it worth noting that we currently lack an evidence base on the relative effectiveness of unidisciplinary and multi-disciplinary public health specialists. Given the innovatory nature of the UK government's policy goals, it would be useful and appropriate for it to commission a robust assessment of the extent to which this policy ultimately contributes to its wider public health policy goals of improving health and reducing inequalities.

In international terms, the UK initiative provides a useful case study of the possibilities and challenges of policy intervention to develop multi-disciplinary public health. As international public health systems are so diverse, the precise details of the UK scheme are unlikely to offer a direct model for many other countries. However, the principles involved (the importance of multi-disciplinary contributions to public health, common high standards, equity in career pathways) are much more generalisable. The risks to public health are increasingly international, and the opportunities to improve health and reduce inequalities increasingly rely on shared learning among international public health professionals. ${ }^{128}$ The prospect of the creation of a European public health agency by the European Union, ${ }^{29}$ for example, is likely to necessitate further European agreement on public health qualifications and competencies. Thus, as more non-medical public health specialists are trained in the UK NHS, the increasing importance of global public health issues and the development of international public health institutions will require further international cooperation in developing multidisciplinary public health careers.

\section{Authors' affiliations \\ D Evans, Bristol North Primary Care Trust, Bristol, UK \\ S Dowling, Dorset and Somerset Health Authority, UK}

Funding: none.
Conflicts of interest: none.

Correspondence to: David Evans, Bristol North Primary Care Trust, King Square House, King Square, Bristol BS2 8EE, UK;

David.Evans@bristolnorth-pct.nhs.uk

Accepted for publication 4 February 2002

\section{REFERENCES}

1 McMichael A, Beaglehole R. The changing global context of public health. Lancet 2000;356:495-9.

2 Joint United Nations Programme on AIDS. Report on the global HIV/AIDS epidemic. Geneva: UNAIDS, 2000

3 Brandt A, Gardner A. Antagonism and accommodation: interpreting the relationship between public health and medicine in the United States during the 20th century. Am J Public Health 2000;90:707-15.

4 Kohler L, Bury J, de Leeuw E, et al. Proposals for collaboration in European public health training. Eur J Public Health 1996;6:70-2.

5 Colomer C, Lindstrom B, O'Dwyer A. European training in public health: a practical experience. Eur J Public Health 1995;5:113-15.

6 Cavallo F, Rimpela A, Normand C, et al. Public health training in Europe: development of European masters degrees in public health. Eur $J$ Public Health $2001 ; 11: 171-3$.

7 McKee M, Mossialos E. Public health and european integration. In Scally G, ed. Progress in public health. London: FT Healthcare, 1997:31-56.

8 Secretary of State for Health. Saving lives: our healthier nation. London: Stationery Office, 1999. (Cm 4386.)

9 Department of Health. The Report of the Chief Medical Officer's project to strengthen the public health function. London: Department of Health, 2001

10 McPherson K. Removing barriers to career development in public health. BM 2000;320:448.

11 Bakhshi S. Career choice in public health should be less restricted. BM 2000;321:113.

12 Edwards N. Public health must make the best use of leadership resources. BM/ 2000;321:767.

13 McPherson K, Taylor S, Coyle E. For and against: public health does not need to be led by doctors. BM 2001;322:1593-6

14 Taylor S, Saunders C. Doctors should lead public health departments. BM 2000;321:112-13.

15 Cornish Y, Knight T. Exploring public health career paths. Birmingham: South East Institute of Public Health/The University of Birmingham Health Services Management Centre/NHS Executive, 2000

16 McPherson K, Fox J. Public health: an organised multi-disciplinary effort In: Scally G, ed. Progress in public health. London: FT Healthcare, 1997.

17 Working Group on Specialist Medical Training. Hospital doctors: training for the future. London: Department of Health, 1993.

18 Faculty of Public Health Medicine of the Royal Colleges of Physicians of the United Kingdom. http://www.Faculty.org.uk/ (accessed 11 January 2002)

19 Patterson W J. Competencies, equivalence and the non-medical public health specialist. 7 July 2000. BM, electronic responses to: For and against: public health does not need to be led by doctors. $B M$ 2001;322:1593-6. (http://bmi.com/) (accessed 11 January 2002).

20 Stewart G. Public health needs other professions. 3 July 2001. BM, electronic responses to: For and against: public health does not need to be led by doctors. BM 2001;322:1593-6. (http://bmi.com/) (accessed 11 January 2002)

21 McAreavey M J. Performance not profession based selection for public health. 5 July 2001. BM, electronic responses to: For and against: public health does not need to be led by doctors. BM 2001;322:1593-6. (http://bmj.com/) (accessed 11 January 2002).

22 Scally G. Public health medicine in a new era. Soc Sci Med 1996:42:777-80

23 Lessof S, Dumelow C, MacPherson K. Feasibility study of the case for national standards for specialist practice in public health: a report for the NHS Executive. London: London School of Hygiene and Tropical Medicine, 1999.

24 Healthwork UK. Project to develop national standards for specialist practice in public health. Spring Bulletin 2000 (http:// www.publichealth.org.uk/bulletin_1.htm). (accessed 11 January 2002).

25 House of Commons Health Committee. Health - second report: public health, 1(Session 2000-01): HC 30-1. London: Stationery Office, 2001.

26 Department of Health. Shifting the balance of power within the NHS: securing delivery. London: Department of Health, 2001

27 Hunt, Lord Philip. Speech to the Faculty of Public Health Medicine at the Royal College of Physicians, London, 13 November 2001. (http://www.fphm.org.uk/Policy/Lord_Hunt_Speech.htm) (accessed 11 January 2002).

28 McKee M, Jacobson B. Public health in Europe. Lancet 2000;356:665-70.

29 Rogers A. European Parliament considers case for European public-health agency. Lancet $2001 ; 358: 2138$ 